Canadian Journal of Family and Youth, 6(1), 2014, pp 189-203

ISSN 1718-9748 () University of Alberta

http://ejournals.library.ualberta.ca/index/php/cjfy

\title{
Growing Up in the Gay Shadow: The Impact of Heterosexual Privilege on Children with Same-Sex Parents
}

\author{
Christopher Lamb
}

\begin{abstract}
Same-sex marriage is currently at the forefront of many political debates worldwide, and one of the main concerns for both sides of the marriage debate is the well-being of children being raised in same-sex families. This paper reviews various areas of research in order to discover whether or not children are at a disadvantage if they are raised in a same-sex family. Findings suggest that while children who grow up in same-sex families face unique challenges that would not occur in heterosexual families, the overall quality of life is comparable to that of children in heterosexual families. Negative attitudes toward same-sex couples raising children are related to the presence of heterosexual privilege in society.
\end{abstract}

Christopher Lamb is currently completing an undergraduate degree in Sociology at MacEwan University. His research interests include gender and family studies. Outside of academic study, Christopher volunteers both on campus and in the community as a MacEwan Ambassador. Upon graduation, Christopher intends to pursue a degree in the field of nursing. 
Lamb

\section{Introduction}

Acceptance of, or discriminatory attitudes towards those who practice homosexuality have varied historically and geographically. In the present day, homosexuality has become a popular focus of the media as countries around the world decide which stance to take on the topic. While countries such as the United States continue to make progress toward fully legalizing same-sex marriage, other countries such as Russia seem to be moving in the opposite direction by making the act of homosexuality illegal.

In Canada, homosexuality was decriminalized in 1969 with an amendment to the Criminal Code. Prior to this time, any sexual activity between individuals of the same sex was punishable by imprisonment (Canadian Heritage, 2012). In 1996, the Canadian Human Rights Act was amended to include sexual orientation as a type of prohibited discrimination. This change guaranteed all individuals, regardless of sexual orientation, the ability to pursue a quality life without the worry of being unjustly treated by employers or organizations. In 2000, the Modernization of Benefits and Obligations Act was passed, allowing same-sex common-law couples to receive the same benefits as heterosexual couples. On July 20, 2005, Bill C-38 was signed into law, which permitted same sex-couples to marry. This further legitimized the rights and freedoms of homosexuals and their families (Canwest News Service, 2005).

According to Statistics Canada (2012), there were 21,015 same-sex married couples reported in the 2011 Census. Including married and common-law same-sex couples, the total number of same-sex couples reported in the 2011 Census was 64, 575. Of those couples, nearly 6,100 had children. The main interest of this paper is to consider the arguments both for and against same-sex couple families raising children. Through careful analysis of both sides of the argument, as well as data based on the actual experiences of children who have grown up in a 
Growing Up in the Gay Shadow

same-sex household, it will be demonstrated that the positive aspects of being raised in a samesex household far outweigh any evidence for negative aspects that have been presented in the literature. Furthermore, it will be demonstrated that the negative views of same-sex families are directly influenced by heterosexual privilege and the hetero-normative expectations of society.

\section{Literature Review}

\section{Impact of Same-Sex Marriage on Children}

One of the main arguments put forward by opponents to same-sex marriage is that the well-being of children will be jeopardized if same-sex couples are permitted to marry (Garrett \& Lantos, 2013). Since becoming the third country in the world to legalize same-sex marriage (the first to being the Netherlands and Belgium), such arguments against same-sex marriage in Canada are increasingly ignored. However, one only has to look south of the boarder to see a whole different experience of the fight for marriage equality. The United States remains divided on legislation allowing same-sex couples to marry, though the current trend is moving toward marriage equality. ${ }^{1}$

Some researchers have argued that same-sex marriage destroys the social foundations that are responsible for guaranteeing a quality life for children. For example, Margaret Somerville (2007) believes that the biological bonds between parent and child are essential for identity formation and development. Somerville argues that not only is heterosexual marriage normal, it is also natural. Because heterosexual marriage is natural and has existed for millennia (p. 180), allowing same-sex couples to create a family separates parenthood from biology.

Somerville asserts that by doing so, children lose their right and ability to know their true origins.

She also believes that both a male and female parent (preferably biological) are necessary in

\footnotetext{
${ }^{1}$ At the current time, seventeen states have adopted same-sex legislation including Hawaii, Illinois, and New Mexico. It is predicted that other states will follow this pattern in the future. (National Conference of State Legislatures, 2014)
} 
order for the child to form a proper gender identity. The bulk of Somerville's argument appears to be aimed directly against the existence of same-sex marriage, though she also is opposed to new reproductive technologies and adoption. While admitting that "sometimes unlinking children from their biological parents is unavoidable and the least harmful option available," she believes that creating the opportunity for such situations to occur is unethical (p. 199). Thus, when it comes to bringing children into a family, Somerville argues that the best possible option for a child is one where it is created naturally through intercourse. Somerville ends by saying that "if marriage involved only adults there is no good reason to oppose same-sex marriage. But for the sake of the children, marriage should remain the union of one man and one woman" (p.199). Expanding on Somerville's work, Patrick Lee (2008) explains what he considers to be the main differences between traditional marriage between a man and a woman and other relationships that are not considered to be marriage. Lee contends that a man and a woman who commit to each other for life, and have the potential to create a human life, are considered to be in a marriage (p. 422). If there is sexual intercourse, a child is a possible outcome of that activity and the parents will be there to raise the child together as one unit. In relationships that have no intention or possibility of having children, sexual intercourse is solely for the purpose of pleasure. Same-sex couples would clearly fall into this category because their sexual activities have no possibility of creating children. Lee further argues this point by arguing that there is a real bodily union created when a man and a woman engage in sexual intercourse (p. 423). For Lee, human beings are complete in every other body system other than the reproductive system. He takes a slightly religious perspective here by stating that the man and woman become one flesh, and this biological bond extends to the children that could potentially be created. Lee calls this union a "basic human good" and believes that such good cannot come from a same-sex 
Growing Up in the Gay Shadow

relationship (p. 423-424). Like Somerville, Lee constantly asserts that the institution of marriage is natural and is the best possible environment for a child to be raised in. He argues that children who are raised by their biological parents will receive more loving care than in any other situation.

Despite the intriguing arguments against same-sex parent families put forward by Somerville (2007) and Lee (2008), it is important to point out that neither argument offers adequate empirical support for their claims. In fact, it is much easier to find intelligible arguments that ably refute their positions. Garrett and Lantos (2013) believe that if the wellbeing of children is to be the main focus of legislation, the opportunity to parent a child should be given to any individual who is found to be financially able to care for a child. In addition, Garrett and Lantos argue that the individuals should be considered as capable of giving a child an adequate existence (p. 560). Garrett and Lantos' position would hold all people accountable for the well-being of their children, instead of assuming that all children in heterosexual families are living the best possible life. By arguing that children can only live the best possible life in a monogamous heterosexual family, the heterosexual families that are not the best environment for children (ie. families with high levels of abuse) become invisible because they fit into the category of the right type of family (p. 560). Garrett and Lantos also feel that preventing samesex marriage on the basis of children's well-being ultimately harms the children of gay parents. Some states that do not allow same-sex marriage allow same-sex parents to adopt children. ${ }^{2}$ Garrett and Lentos believe that such a combination makes the families of these children appear illegitimate and cannot possibly foster a decent developmental environment (p. 562).

In Canada, the central reason for legalizing same-sex marriage was not the well-being of children. In fact, the majority of same-sex couples in Canada live alone (Statistics Canada,

\footnotetext{
${ }^{2}$ Such states include Arkansas and Indiana. (National Conference of State Legislatures, 2014)
} 
2012). More than anything, the decision to legalize same-sex marriage was influenced mainly by human rights. ${ }^{3}$ It will be interesting to see how the family landscape will change in the coming years as more same-sex couples marry. Research has shown that legalizing same-sex marriage raises marriage rates, reduces abortion, and decreases the number of children who grow up in single parent families (Langbein \& Yost, 2009). Though it is not the case that children of single parent households will lead poor quality lives, economic burdens almost always fall harder on single parents, particularly if they have lower levels of education and are female (Garrett \& Lantos, 2013). Also, while researchers such as Somerville (2007) contend that children are far better off with their biological parents, it could be argued that biological parents are not always the best choice for in terms of raising children. After all, many children are raised by single parents or other family members such as grandparents. Looking at the actual experiences of the children who live within a family headed by a same-sex couple reveals much more about the necessity of having a family legitimized under law.

\section{The Experiences of Children in Same-Sex Families}

While much of the literature has focused on whether or not same-sex marriage should be legal based on the repercussions for children, an important viewpoint often left out is that of the children being raised in same-sex households. In light of this, Leddy et al. (2012) collected the opinions and experiences of thirty-two adults who were raised in lesbian families. When asked about the positive aspects of growing up in a lesbian household, the majority of participants felt that they grew up in a loving environment where they were taught values of acceptance and learned to appreciate and accept others. The participants also felt that they had a broader sense of what family was, something they felt would not have been possible had they grown up in a

\footnotetext{
${ }^{3}$ For more detail on the human rights argument that was used and the resulting change to the marriage law, refer to the Parliament of Canada, Bill C-38, The Civil Marriage Act 2005.
} 
Growing Up in the Gay Shadow

traditional heterosexual family (p. 248). When asked about the reactions of peers, the majority of participants felt that they were received rather positively after revealing their family to others. While some participants did admit to being victims of varying degrees of teasing or bullying, these individuals felt that their family structure made them more resilient and able to ignore negative responses in the future (p. 252). In strong opposition to the viewpoint of researchers such as Somerville (2007), Leddy et al. concluded that children do not need to be protected from same-sex family structures. Their findings show that children raised by lesbian parents are more open to differences among people than their counterparts raised in heterosexual families and that lesbian mothers are able to provide a quality of life to their children that would be found in any family (2012, p. 256).

While Leddy et al. (2012) collected data from an adult sample, Welsh (2011) conducted a similar study from the viewpoint of fourteen adolescents who were being raised in same-sex families. As was found by Leddy et al., the participants felt they had gained an expanded view of what makes a family. They defined their experiences of family with expressions of love, tolerance, and strong support (p. 64). While their close family relationships were consistently nurturing and loving, Welsh found a common frustration around the challenges and struggles faced by the participants in early adolescence. Many of the participants reported feelings of loss and guilt associated with early to mid-adolescence. Welsh argues that while this period of life is often difficult, the sexual orientation of the participants' parents added an extra challenge because they were forced to integrate their family identity into their personal identity (p. 65). Because participants felt the need to hide their family identity, they felt significantly different from their peers who were part of heterosexual families. 
Lamb

Welsh also discusses the role of the media in the frustration felt by the participants. With media images influencing public opinion of same-sex marriage and families, the participants constantly felt they had to defend their family to the world (p. 60). Interestingly, some of the participants missed the feeling of struggle when they moved away to college. Having always defined themselves partially by their family identity, some participants felt lost. Being characterized by the sexual orientation of their parents also led many participants to feel like they weren't permitted to make mistakes within social circles outside of their families. As one participant put it, "That's how people knew me...the girl with two gay dads...that was like my image" (p. 57). The participants felt the need to be over-achievers with flawless personalities, even though they sometimes wanted to just let their guards down and relax. If they ever took a misstep, they were afraid that their mistake would be blamed on the fact that they were the children of same-sex couples. While the struggles mentioned by the participants seem particularly suited to having same-sex parents, it is important to point out that the problems all stem from outside of the family unit. In other words, the participants consistently stated that they had a strong loving family unit, and this part of their identity was tested only by outside forces such as the media and peers. Welsh states accurately that "in so many ways, this is a group of youngsters who are in the spotlight, but they aren't being seen" (p. 67).

The studies by Leddy et al. (2012) and Welsh (2011) clearly illustrate that families headed by same-sex couples are able to raise well-adjusted individuals capable of understanding the world around them and are able to function normally even with pressures placed on them by the norms of a hetero-normative society. These studies lend support to legalizing same-sex marriage for the purpose of legitimizing the family relationship within society in general. While same-sex marriage is legal in Canada, it is still a fairly new concept to many people. As of 2011, 
Growing Up in the Gay Shadow

same-sex couples account for $0.8 \%$ of all couples in Canada (Statistics Canada, 2012). This percentage drops even more if only same-sex parents with children are considered. Thus, while same-sex families are more legitimized in Canada, the struggles felt by the participants of Leddy et al. and Welsh could still be experienced by Canadian children of same-sex families. These hardships appear to be caused directly by social privilege, and more accurately, heterosexual privilege.

\section{Heterosexual Privilege and the Hetero-normative Society}

The concept of privilege began to receive significant attention following Peggy McIntosh's paper on white privilege (1990). Within the paper, McIntosh explored the way that society allows whiteness to remain invisible by affording advantages that are unavailable or difficult to obtain by individuals of minority races and ethnicities. Since McIntosh's initial work, the study of privilege has expanded to include many areas of social reality. According to Black and Stone (2005), social privilege is defined by five components (p. 244). First, privilege is a special advantage that is neither common nor universal. Second, it is granted and cannot be earned by an individual's talent or ability. Third, it is an entitlement to a desirable status or rank within society. Fourth, privilege gives the recipient certain benefits that are either unavailable to those outside of the privileged group or have negative implications for those outside of the privileged group. Lastly, those groups and individuals with privilege are usually unaware of the advantages they possess. Social privilege can occur within the domains of race/ethnicity, gender, socioeconomic status, age, religious affiliation, degree of ableness, and sexual orientation (pp. 245-246).

An intriguing study by Cole et al. (2012) analyzed newspaper articles in order to determine whether or not the arguments about the naturalness of marriage privileged 
heterosexual individuals. Based on an analysis of 273 articles, they found that the majority of articles contained at least one argument about the naturalness of certain relationships (p. 56). Many of the articles argued that marriage had existed the way it was for centuries and that marriage laws should not change. Cole et al. assert that the reason people believe that marriage laws have remained unchanged for so long is based on the belief that the status quo should be privileged and that the tradition of marriage is a social good (p.57). By presenting certain social arrangements such as marriage and family formation as a natural occurrence, attention is removed from injustice and inequality. Certain groups are able to have their privilege reinforced because all other groups are seen as unnatural or deviant. The form of privilege most pertinent to the current discussion is heterosexual privilege.

In looking at the experiences of same-sex families and the children being raised in them, privilege of heterosexuality seems to have a powerful impact on the experiences of these families. Because heterosexuality is viewed as the norm, any sexual orientation that deviates from that norm is considered to be deviant and unnatural (Black \& Stone, 2005, p. 248). As discussed previously in the research by Welsh (2011), the participants felt that their identities were at least partially defined by their parent's sexual orientation. Many of them had to deal with a 'coming out' process when dealing with their peers. Thus, even though the participants themselves did not necessarily identify as homosexual, they were challenged with the societal norms of heterosexuality. Black and Stone assert that heterosexual privilege differs greatly from other forms of privilege in that homosexuality is often argued to be a choice whereas race and disability are unchangeable (2005, p. 248). The idea of homosexuality as a choice has been a popular claim within the media, as well as within religious and political circles. The children of same-sex couples become marginalized in an identical way to their parents. In Canada, though 
Growing Up in the Gay Shadow

same-sex marriage is legal, the dominant norms of society place privilege in the hands of heterosexual individuals. With same-sex families accounting for such a small percentage of Canadian families, it follows that the children of same-sex couples do and will continue to experience the negative effects of heterosexual privilege. They are unlikely, however, to receive the same considerations that other marginalized groups receive because their parents' sexual orientation is seen to be a choice.

The concept of heterosexual privilege becomes problematic for the arguments presented by Somerville (2007) and Lee (2008). Both have argued that children will receive the best upbringing if they are with their biological mother and father because of the natural bond between a man and a woman who are committed to each other for life. Being of a dominant group in society (i.e. heterosexual), Somerville and Lee believe that what is natural is their lived experiences. Because they equate natural with good, they erroneously believe that heterosexual families constitute what is good. The traditional institution of marriage constitutes what is good. All other couples who would attempt to claim the title of marriage for their relationships are in fact not living in a real marriage. Thus, according to Somerville and Lee, those individuals are not living in a real family and should not be permitted to raise children.

\section{Conclusion}

Based on the research that has been collected for this paper, it becomes possible to draw many conclusions. First, the research appears to support the idea that same-sex families are just as able to raise well-adjusted children as heterosexual families are. The research by Somerville (2007) and Lee (2008) argues against the ability of same-sex families to provide a quality life for children, but these arguments are not sufficient when compared to the growing body of research in support of same-sex families. The work of Leddy et al. (2012) and Welsh (2011) revealed the 
strong familial bonds that children experience in same-sex families. Both studies reported an expanded sense of family and belonging within same-sex families. Also, it is possible that children in same-sex families may be more resilient and considerate of others because they are growing up in a loving home that is marginalized by society.

The legalization of same-sex marriage allows the children of same-sex parents to feel like their family is legitimized. While legalization does not remove or replace the dominant social norms, children are able to relate to their peers on a more equal level when they can say that their family is equal to heterosexual families. The legalization of same-sex marriage may also help to shift public opinion of homosexuality, though the extent of that shift was not explored in the current research. As suggested by Garrett and Lantos (2013), legalizing same-sex marriage should be completely about guaranteeing the well-being of children, since denying the right of parents to marry further illegitimates the same-sex families who have children.

Adolescents in same-sex families face the extra challenge of integrating their family identity with their own personal identity. They must negotiate their relationships with their peers and society in general, deciding when and how to 'come out' as a child of same-sex parents. When their family identity is revealed, they feel defined by it. Stereotypes and opinions offered by media, politicians, and other institutions make them feel the need to defend their family. For these reasons, it is argued that dominant social norms such as heteronormativity create a stressful situation for children of same-sex parents that would not be experienced by children of heterosexual parents. The need to constantly defend their family while simultaneously trying to prove their own self-worth creates a situation where they feel judged as one-dimensional. That is, even though they have an identity made up of many factors, they feel that society defines them solely on the sexual orientation of their parents. 
Growing Up in the Gay Shadow

The main conclusion to be drawn from the reviewed literature is that the majority of negative aspects regarding same-sex families are external to the family unit. In other words, it is the reactions and interpretations of society that create and reinforce the beliefs that same-sex parents are incapable of raising children. Society's opinions of same-sex families are primarily shaped through heterosexual privilege. Because heterosexuality is the dominant form of sexuality in society, all other sexual orientations are seen as unnatural and deviant. By association, children of same-sex parents will feel marginalized and be subjected to the same negative implications of heterosexual privilege. The majority of arguments made against same-sex families that present them as unnatural are deeply rooted in heterosexual privilege. Regardless of whether or not privileged members of society are aware of their privilege, the privileged status allows them to remain distant from those who are oppressed.

Same-sex marriage has been legalized in Canada for nearly a decade and it is possible that the trend of same-sex couples marrying will continue to increase. As more same-sex couples create families, there will be much opportunity for research into the lives of the children in those families. It is suggested that more focus be placed on the actual experiences of children growing up in such a family, as the research on the topic is lacking. It is also suggested that awareness of heterosexual privilege be continually promoted. While raising awareness will be beneficial for all individuals who do not fit neatly into the heterosexual box, the real benefit will be to the children of same-sex parents. 
Lamb

\section{References}

Black, L. L., \& Stone, D. (2005). Expanding the definition of privilege: The concept of social privilege. Journal Of Multicultural Counseling And Development, 33(4), 243-255.

Canadian Heritage. (2012). Sexual orientation and human rights. Retrieved from http://www.pch.gc.ca/pgm/pdp-hrp/canada/sxrnt-eng.cfm

Canwest News Service. (2005). Chronology: Same-sex marriage. Retrieved from http://www.canada.com/national/story.html?id=41a2cfbb-5124-4527-8627-3af8aa1919de

Cole, E. R., Avery, L. R., Dodson, C., \& Goodman, K. D. (2012). Against nature: How arguments about the naturalness of marriage privilege heterosexuality. Journal Of Social Issues, 68(1), 46-62.

Erich, S., Kanenberg, H., Case, K., Allen, T., \& Bogdanos, T. (2009). An empirical analysis of factors affecting adolescent attachment in adoptive families with homosexual and straight parents. Children \& Youth Services Review, 31(3), 398-404.

Garrett, J. R., \& Lantos, J. D. (2013). Marriage and the well-being of children. Pediatrics, 131(3), 559-563.

Langbein, L., \& Yost, M. A. (2009). Same-sex marriage and negative externalities. Social Science Quarterly (Wiley-Blackwell), 90(2), 292-308.

Leddy, A., Gartrell, N., \& Bos, H. (2012). Growing up in a lesbian family: The life experiences of the adult daughters and sons of lesbian mothers. Journal of GLBT Family Studies, 8(3), 243-257.

Lee, P. (2008). Marriage, procreation, and same-sex unions. Monist, 91(3/4), 422-438.

McIntosh, P. (1990). White privilege: Unpacking the invisible knapsack. Independent School, 49(2), 31. 
Growing Up in the Gay Shadow

National Conference of State Legislatures (2014). Defining Marriage: State Defense of Marriage Laws and Same-Sex Marriage. Retrieved from http://www.ncsl.org/research/humanservices/same-sex-marriage-overview.aspx

Parliament of Canada. Bill C-38, The Civil Marriage Act, 2005. Online access: http://www.parl.gc.ca/About/Parliament/LegislativeSummaries/bills_ls.asp?ls=c38\&Parl $=38 \& \operatorname{Ses}=1$

Rose, H. (2012). Canada's same-sex marriage law: Exception to or exemplar of Canada's family policy? Journal of Child \& Family Studies, 21(1), 88-94.

Ryan, S. (2007). Parent-Child interaction styles between gay and lesbian parents and their adopted children. Journal of GLBT Family Studies, 3(2/3), 105-132.

Somerville, M. (2007). Children's human rights and unlinking child-parent biological bonds with adoption, same-sex marriage and new reproductive technologies. Journal Of Family Studies, 13(2), 179-201.

Statistics Canada. (2012). Portrait of Families and Living Arrangements in Canada. Statistics Canada Catalogue no. 98-312-X2011001. Retrieved from http://www12.statcan.ca/census-recensement/2011/as-sa/98-312-x/98-312-x2011001eng.cfm

Welsh, M. G. (2011). Growing up in a same-sex parented family: The adolescent voice of experience. Journal of GLBT Family Studies, 7(1/2), 49-71. 